\title{
Acculturation and Re-entry Culture Confrontation: the Case of Development Workers
}

\author{
Petia Genkova ${ }^{1}$ (D) - Johanna Pollinger ${ }^{2}$
}

Accepted: 24 May 2021 /Published online: 17 July 2021

(C) The Author(s) 2021

\begin{abstract}
The study at hand investigated the reintegration of development workers in terms of the sociocultural adaption and societal engagement after the return to the home country. The investigation had a cross-sectional design with 311 returned development workers. The results show that the sociocultural adaption of development workers several years after their return was significantly related to their job-related personality. However, there were no group differences for cultural distance. Results indicate that individuals who are more actively working together with others might be more likely to readapt well after return. Moreover, the results show that experienced social appreciation of the stay abroad is a relevant predictor of further engagement. Considering that appreciation is very likely to be a central motive for development workers, this underlines the importance for organizations to worship the engagement of repatriating development workers by offering support as well as by creating a culture in which extraordinary engagement is honored sufficiently.
\end{abstract}

Keywords Expatriates · Homecoming · Reintegration · Development work · Societal engagement

\section{Introduction}

Individuals who lived abroad for occupational or private reasons are described as expatriates. This terminology was established and is more present in business contexts but actually describes any kind of international assignment, such as, e.g., development workers, who spend a period of time in a foreign country in order to support

Petia Genkova

petia@genkova.de

1 Osnabrueck University of Applied Sciences Faculty of Business Management and Social Sciences, Caprivistr. 30A, 49076 Osnabrück, Germany

2 Lund University, Lund, Sweden 
humanitarian goals and help locals in many ways (Lackner, 2008). The reintegration process, also known as return or rehabilitation, describes the final phase of such an international assignment. Those three terms are usually used as synonyms (Kompreni, 2009). This definition implies that an individual needs to go through a process of readaption to its home country, after spending time in and thus adapting to another culture (Rossi, 2015; Ward \& Geeraert, 2016). While acculturation research implies possible difficulties in the acculturation as well as in the reculturation process (e.g., Scharbert, 2015), there is a lack of investigation of reintegration processes for specific groups, like development workers. Previous studies have focused on the returning processes of co-workers from multinational companies and homecoming students (Adler, 1981; Hurn, 1999; Suutari \& Välimaa, 2002) as well as on retirement remigration (e.g., Assari, 2020). Few research has addressed the target group of returning professionals in the field of development cooperation. Those were mainly studies on trends in the field of posting of development workers, though reporting significant periods of unemployment after the return and emphasizing the insufficient understanding of reculturation process in the field of development work (Roxin et al., 2015; Koch \& Widmaier, 2006).

Since engagement of development workers with the unfamiliar culture is most likely more profound compared to economic expatriates, they might adapt stronger to local cultural circumstances. Thus, the rehabilitation in the home country might be more difficult, and the aspects of sociocultural adaption and further societal engagement after return therefore require further consideration. Previous studies identified the meaning of job-related personality characteristics and the way individuals experience and deal with job-related challenges as potential predictors of reculturation, under consideration of the cultural distance between host and home culture (Wolff, 2017). In order to contribute to further reintegration procedures, the aim of this study was thus to examine the relationship of job-related personality of homecoming German development workers and experienced appreciation with sociocultural adaption and further societal engagement also considering the cultural distance between host and home culture as possibly relevant variable.

\section{Literature Review}

During the inquiry of the current study at hand, two studies stood out: the evaluation of the "German Evaluation Institution of Development Cooperation" (Roxin et al., 2015) about Development Workers - a personnel instrument of German development cooperation and the study about the occupational and social reintegration of former development worker by Koch \& Widmaier, 2006). The latter was conducted in 2006, commissioned by the "Project Group of Development Services" (AGdD). One thousand five homecomers as well as 198 scholarship holders were questioned from six renowned development services. The results of the research showed that $70 \%$ of the homecomers in the field of development services were affected by unemployment. Unemployment was 10 months on average, which is below the level of long-term unemployment. One conclusion of this research was therefore that homecomers in the field of development cooperation are not affected by unemployment substantially longer than other job seekers. On the other hand, the occupational group of 
development workers is described by the employment office as the following: "People, who have international work experience, flexibility, resilience and multilingualism, so to say special competences through their time abroad, usually can be categorized as a well placeable group." (Koch \& Widmaier, 2006, p. 5). Both studies emphasize the need to further investigate the returning process of development workers, their adaption, and engagement after return.

\section{The Role of Returning Home from International Assignments}

Wirth (1992), in line with Adler (1981), describes the return from a stay abroad as part of a cycle, which already starts with the planning of the international assignment. Accordingly, Sussman (2002, p. 1) describes the process as the following: "The nature of the sojourner is one of a cycle: moving to a new country and moving home, the process of adjustment and the outcome of adaption, culture shock and reverse shock." More precisely, the international assignment starts with the decision whether it is necessary to post a co-worker followed by the selection of suitable employees and the actual planning of the international assignment. The assignment is finalized by a preparation for return or at least a debriefing. After the return, the individual goes through a process rehabilitation (Adler, 1981). In more easy words, this model considers major problems for sojourners when going abroad as well as when coming home. Acculturation theory explains the experiences and impediments for individuals and groups adapting to each other when someone goes abroad in terms of culture (Redfield et al., 1936; Sam \& Berry, 2011; Ward \& Geeraert, 2016). Thomas (2003) defines culture as a shared psychological orientation system, providing identity and norms for perception, thinking, and acting. This approach explains sufficiently how people struggle to interact with members of a foreign culture, even when both of them speak the same language. When norms and standards for interpersonal interaction differ to a certain degree, the deeper meaning of words and actions gets lost or misinterpreted, which causes major stress (Barmeyer, 2010).

\section{Acculturation and Reculturation}

Getting in contact with another culture even for only a couple of months causes individuals to significantly change perception, thinking, and acting, adapting to the new cultural environment (Tracy-Ventura et al., 2016; Wolff, 2017). Ward (2001) differentiates between sociocultural and psychological aspects of adaption to a host culture. Sociocultural adaption refers to skills, abilities, and behavioral patterns which are needed when interacting with another culture. This also contains the ability to deal with problems that occur as well as being able to carry out daily tasks (Neto, 2012). Psychological adaption refers mainly to affective dimensions, such as feeling good living in the respective culture. Moreover, this includes a certain degree of identification with the host culture (Ward 2001). While both dimensions of acculturation are interconnected, they are seen as distinct from one another (Neto, 2012).

Even though Ward (2001) provided a model that gained broad interest and acceptance, he did not consider the return of an expatriate. After the beginning of acculturation studies, Gullahorn and Gullahorn (1963) proposed a model for satisfaction during an expatriation process, which was W-shaped. It considered the re- 
acculturation process, based on the observation that returning home is rarely what expatriates expect it to be. Therefore, according to Gullahorn and Gullahorn (1963), satisfaction decreases during the acculturation to the host culture and increases in terms of better adaption. When the expatriate comes home, the process repeats, and satisfaction decreases and increases after a certain time. There has been strong empirical support for this perspective (e.g., Neto, 2012; Georgas \& Papastylianou, 1994: Kim, 2008), indicating that individuals have to re-adapt, when coming home, given that satisfaction sufficiently displays the current level of adaption to the social environment.

The three-phase model from Scharbert (2015) takes a closer look at this second decrease of satisfaction, which refers to both psychological and sociocultural adaption of occupational expatriates. He argues reasonably that a differentiation in sociocultural and psychological adaption is not promising in this context, as they might simplify the complexity of acculturation and the related processes. In his model, he focuses on a more cognitive- and behavior-oriented perspective, in which the return already starts abroad and the characteristic behavioral patterns are divided in three distinct phases: anticipation, accommodation, and adaption phase.

- Anticipation: In the first phase, the expatriate imagines a picture of possible returning scenarios. During the anticipation phase, expectations concerning the career development are especially high. If expectations are fulfilled remains uncertain at that point in time.

- Accommodation: In the subsequent phase, the homecomer tries to rehabilitate him/ herself, and issues can arise due to the discrepancy between expectations and the encountered reality. The accommodation phase comprises the shock phase during the returning period.

- Adaption: For this phase, Scharbert (2015) defined four reactions, which can follow such a shock: adaption, rejection, dissociation/disengagement, or dependency. The former describes the coping of differences, followed by rejection. Hereby, the co-worker stays in the organization; however, he/she does not try to adapt and develops negative attitudes towards the organization. The dissociation/disengagement describes the total delinking from the organization. Dependency as reaction creates a full adaption of the co-worker to the old working environment, without recognizing the learned behavioral patterns from the international assignment. Finally, rehabilitation is completed with the adaption of the homecomers.

During this process, the identification with the home country and the bilateral acceptance are the main goals (Scharbert, 2015). Thereby, Scharbert (2015) emphasizes that a stronger acculturation to another culture is linked to stronger conflicts in the host culture, which bases on the idea of the W-Curve model of Gullahorn and Gullahorn (1963). Accordingly, a stronger adaption to another culture is expected to be related to less adaption to the home country afterwards.

\section{Personality of Returnees and Cultural Distance}

Another underlying assumption of acculturation theory is that living in another than the home country influences an individual's personality and behavior (Mapp, 2012). To 
describe the possible results of a stay abroad in detail would exceed the scope of this article. However, the experiences, which were gathered during this time, lead to a change in people. Often their task comprises provision of aid for people in hazardous situations with no money, no shelter, and no food. Such experiences can be substantially more traumatic and imprinting than a regular office job and a stay in a decent neighborhood. Additionally, returning to the comparably wealthy homeland might create cognitive dissonance between the experienced grievances and the own lavish lifestyle. Tracy-Ventura et al. (2016) outline in their resume on character development that such experiences, life events, might lead to significant changes in perspectives and character traits. Moreover, Wolff (2017) describes that in such special situations, people are able to choose certain behaviors, which are equivalent to invest in the expression of a certain trait (Roberts et al., 2005). Berry et al. (2011) as well as Ward and Geeraert (2016) additionally demonstrate that changes in personality as well as the acculturation process itself depends on the cultural distance between host and home culture, as difficulties in intercultural interaction are understood as the result of two or more orientation systems not being congruent, also depending on the individual's personality and competences. The concept of cultural distance used in this study is based on Hofstede's dimensions of cultural distance (Kristjánsdóttir et al., 2017; Mägdefrau \& Genkova, 2014). The general concept is to compare various cultural manifestations on these five dimensions, which are power distance, individualism, masculinity, uncertainty avoidance, and long-term orientation. Considering that the ex- and return process is a cyclic one, it suggests that both, the described adaption and reculturation, strongly depend on the relation and the perceived differences between an individual's host and home culture.

\section{Further Engagement of Returned Development Workers}

The evaluation of the DEval about Development Workers - a personnel instrument of German development cooperation 2015 (Roxin et al., 2015) was conducted on behalf of the German federal ministry of economic cooperation (BMZ). Sense and purpose of this undertaking was the gathering of empirically founded insights and guidance concerning the efficiency of development workers and accompanied factors. The reintegration of the homecomers and their societal engagement were of minor importance for the DEval study. Yet, since those two aspects are the focus of the study at hand, the following will only concern related results, which reflect the participation in the home country after return in form of social engagement. Societal engagement after the return to the home country is an important factor to rule out the possibility that the social work itself caused the workers to discontinue with their occupation as social workers. In more detail, the experience abroad changed their attitude towards people in need and ultimately their motivation to continue working in this field. In the study of Roxin et al. (2015), the extent of the societal engagement was obtained via four topic fields: the extent and the kind of societal engagement, the motivation for societal engagement, the barriers for societal engagement, and the self-evaluation of efficiency. The occupational situation of the homecomers was assessed via the questions: "How many homecomers had difficulties with the occupational return? Are the specific needs for support services of repatriates able to explain difficulties with the occupational return?" (Roxin et al., 2015, p. 106 - 112). 
To summarize the results, the motivation to help and engage in social activities prevails. Even after the return, a change in attitude regarding pro social activities did not occur. The biggest obstacle, which hindered societal engagement, was the issues that engagement and the timely duty of work and family are hard to harmonize, which accentuates the influence of external factors but neglects intrinsic motivations.

\section{The Current Study}

The current study aims to gain insights in the reculturation of returned German development workers regarding their sociocultural adaption and their further societal engagement. Therefore, we consider the cultural distance between home and host culture to be related to reculturation processes. Wolff (2017) suggest to investigate whether the adaption of homecomers differs for different levels of cultural distance. Therefore, the study at hand expected that the cultural distance between the host and home culture of development workers influenced their sociocultural adaption when coming home. According to Scharbert (2015), we do not differentiate in sociocultural and psychological adaption, rather than considering a scale that implements relevant aspects from both dimensions, even though it is called Sociocultural Adaption Scale. We assume that even years after the return, there should be differences in the adaption of repatriates, depending on their experiences of cultural distance.

Furthermore, Wolff (2017) suggests that there are differences in the jobrelated personality of repatriates depending on their experiences abroad. Consequently, those who experienced a higher degree of cultural differences might have different attitudes towards work and show differing patterns of experiencing stress and social support. We thus assume that there are significant differences in job-related experiential and behavioral patterns. On the other hand, there are indications that the personality and especially the job-related personality relate to the adaption performance, predicting the behavioral potential to change patterns, to interact with host culture members in an efficient way, and especially to deal with the stress, if interaction does not go as planned (Panicacci \& Dewaele, 2017). However, it remains unclear whether this relates to the reculturation as well. Thus, we assume that the adaption to the home culture after return is different for different experiential and behavioral patterns.

As demonstrated above, in the DEval study, Roxin et al. (2015) did not examine internal motivations of development workers to further engage after their return. Dieleman et al. (2006) showed in a qualitative explorative study appreciation of engagement as a key factor for further motivation among health workers in Mali, and there is no reason why this should change for those development workers who came home again. As appreciation is a key factor to support the internal motivation, according to Kauffeld (2014), the study at hand analyzes how development worker repatriates experience in the appreciation of their work and whether it influences their further social engagement. 
Hypothesis 1: The manifestation of sociocultural adaption in the home country differs significantly in regard to cultural distance between the host country and the home country.

Hypothesis 2:

a. The manifestation of occupational-related behavioral and experience patterns differs significantly in regard to cultural distance between host country and home country.

b. The sociocultural adaption of the homecomers differs significantly in regard to the manifestation of occupational-related behavioral and experience patterns.

Hypothesis 3: The experienced appreciation for the accomplished assignment abroad predicts the societal engagement of development workers after their return.

\section{Method}

In order to test the hypotheses, we conducted a cross-sectional study using an online survey distributed by a variety of organizations which send development workers abroad. The survey contained several questionnaires, which are explained in the following.

\section{Measurement Tools}

As measurement tools, the Work-Related Behavior and Experience Pattern Scale (in German AVEM) and the Sociocultural Adaption Scale (SCAS) were used as well as demographic questions about the development worker were asked. Finally, the questionnaire contained questions about the experiences of their international assignment, how did they stay, and in which country they were.

The Work-Related Behavioral and Experience Pattern Scale (AVEM) by Schaarschmidt and Fischer (1996) is an established tool to predict health enhancing and endangering behaviors and experiences in the working environment. With those manifestations, fitting interventions can be derived, which can facilitate the health and the satisfaction of development workers in a context of return in our case. The test assesses work-related behaviors and perceptions on the dimensions engagement, resistance, and emotion on 44 Likert scale items and then clusters participants into four work-related behavioral and experiential patterns. The following manifestations are described: pattern G (health = Gesundheit (German)) describes a high engagement with work, highly developed resilience towards burdens, a positive sense of life, and socalled physical health. Pattern S (rest = Schonung (German)) is characterized by extensive resting tendencies towards occupational demands. Pattern A (risk in the sense of overextension) describes the excessive engagement (overextension) with limited sense of life and lowered resilience towards demands. The fourth and final pattern B (risk in the sense of chronical state of exhaustion and resignation) is determined by the prevailing experience of overextension, exhaustion, and resignation (Schaarschmidt \& Fischer, 2008). 
The Sociocultural Adaption Scale (SCAS), according to Ward and Kennedy (1999), is a measurement tool for the assessment of adaption to other cultures and their facets. The long scale for the identification of adaption factors was originally used for the measurement of intercultural competence in different behavioral sections, whereby the latter conceptualized items rather assess cognitive competence (Zick, 2010). The Sociocultural Adaption Scale is a flexible assessment tool, which can smoothly be adapted to the characteristics of the participants (Ward \& Kennedy, 1999). The questionnaire contained 325 -point Likert scale self-statements about the extent of the difficulties that sojourners experience in different situations on two dimensions, behavioral adaption $(\alpha=.76)$ and cognitive adaption $(\alpha=.81)$. Respective sub-dimensions are cultural empathy and relatedness as well as impersonal endeavors and perils (Ward \& Kennedy, 1999).

Cultural distance was assessed via using the information about the countries, in which the development workers fulfilled their international assignment and pooling them to the regions of the globe study of House et al. (2004). According to House et al. (2004), the members of one cluster are more similar to one another then to the other clusters in terms of "Shared motives, values, beliefs, identities and interpretations or meanings of significant happenings, which are the result of shared experiences of members of a collective, which are passed on through generations and age groups" (House et al., 2004, p. 8). As operationalizing cultural distance as a metric variable is rather problematic (Wolff, 2017), we decided to compare the cultural clusters of House et al. (2004) in order to identify possible differences between cultural clusters.

\section{Sample}

During the 6-week period of analysis, 316 development workers, which completed their assignment abroad and returned to their home country, participated in the survey. Five participants were excluded from the sample, due to missing or extreme answers. The age ranged between 29 and 82 . The average age was 50.01 . With $27.3 \%$, the participants between 30 and 40 years built the biggest group, followed by development workers between 50 and 60 with $25 \%$. With $57.8 \%$, more than half of the questioned development workers were married. $32.8 \%$ were single and $7.8 \%$ divorced. The other $1.8 \%$ either were widowed or did not state their family status. The results reveal that on average, participants returned home before 5 years have passed $(\mathrm{M}=5.26$ and $\mathrm{SD}=1.961)$. Sixteen percent of the surveyed development workers had a migration background (second generation); none of them was a first-generation migrant themselves though.

Table 1 displays the host countries and the respective cultural clusters, as well as the number of participants in this study who stayed there. Usually, the category Europe is further divided, but because of the few statements in this region, they were pooled. The biggest group went to Latin America followed by the sub-Saharan region in Africa, Europe (pooled), and Southeast Asia. Only eleven participants worked in an Anglophone region.

The median of the duration of stay was 6 months, which underlines that the actual middle deviates from the average value. In general, all statements can be divided into eight groups; see Table $2.36 .7 \%$ of the questioned people indicated that it took less than six months to feel fully integrated. $12.5 \%$ stated that it took one to two years. $7.8 \%$ said that the feeling of integration was immediately present and no time was needed to re-establish it. Overall, the minimum time required ranges from 0 to 99 months ( 8.25 years). 
Table 1 Global country clusters and information about the sample

\begin{tabular}{llll}
\hline Cluster & $\begin{array}{l}\text { Global } \\
\text { definition }\end{array}$ & Sending countries of questionees & N \\
\hline 1 & Europe & Croatia, Poland, Ukraine, Serbia & 67 \\
2 & Latin America & Bolivia, Brazil, Chile, Costa Rica, Dominican Republic, & 102 \\
& & Ecuador, El Salvador, Guatemala, Haiti, Mexico, & \\
& & Nicaragua, Peru & 11 \\
3 & Anglo & South Africa & 74 \\
4 & sub-Saharan Africa & Burkina Faso, Burundi, DR Kongo, Ghana, Cameroon, & 25 \\
& & Kenia, Lesotho, Mozambique, Sambia, Sierra Leone, & 32 \\
5 & Middle East & Zimbabwe, Tanzania, Togo, Uganda & \\
& South East Asia & Afghanistan, Indonesia, Cambodia, Laos, Myanmar, & \\
& & Nepal. Tajikistan, Uzbekistan, Vietnam, Philippines & \\
\hline
\end{tabular}

For the question that concerned factors, which hampered the reintegration process the most, participants were offered ten different categories. They were assigned to bring them in order, according to their subjective importance. Not all categories had to be chosen, to ensure the selection of those categories that really affected the reintegration process. The following categories were offered: preparation and house moving, financial and taxation matters, re-entry-position and career planning, culture shock and adaption to the home culture (including the family), educational system and education of the children, change of the working environment, stress management, communication problems, new social contacts and networks, as well as the category others.

The distribution of the AVEM patterns was as follows: 15\% of the participants showed manifestations in pattern $\mathrm{G}$ and therefore showed healthy behavior. The majority of the questioned people showed $47 \%$ with the resting pattern $\mathrm{S}$, followed by around $25 \%$ with risk patterns (type A and type B). Seven percent could not be assigned or displayed a pattern combination (6\%). Pre-tests regarding possible covariates revealed that there were no significant relationships between migration background (yes/no), sex and age, and the dependent and independent variables of this study. Furthermore, manually mapping countries of origin of parents showed that participants from a certain region rarely went there for development work.

Table 2 Duration until feeling of reintegration

Duration until feeling of reintegration

\begin{tabular}{|c|c|c|c|c|c|}
\hline Years & None & $<1 / 2$ & $1 / 2$ & $1 / 2-1$ & 1 \\
\hline$\%$ & $(7.8 \%)$ & $36.7 \%)$ & $(10.2 \%)$ & $(4.7 \%)$ & $12.5 \%)$ \\
\hline \multirow[t]{4}{*}{$\mathrm{N}$} & 24 & 114 & 32 & 15 & 39 \\
\hline & $1-2$ & 2 & $>2$ & total & \\
\hline & $(12.5 \%)$ & $(8.6 \%)$ & $(7 \%)$ & 100 & \\
\hline & 39 & 27 & 21 & 311 & \\
\hline
\end{tabular}




\section{Results}

\section{Testing Hypothesis 1}

We conducted pairwise t-tests to find out whether cultural distance between the host country and the home country had influence on the sociocultural adaption. The results of the pairwise comparison are listed in Table 3 and show that sociocultural adaption was significantly different only for the Anglo-sub-Saharan Africa with $t(35)=2.073, p$ $=.05$ and Anglo-Middle East with $\mathrm{t}(7)=3.44, \mathrm{p}=.01$. The rest of the means did not differ significantly concerning the sending country.

\section{Testing Hypothesis 2a}

In order to test hypotheses $2 \mathrm{a}$ and $\mathrm{b}$, we performed chi-square tests, to reveal whether there is a statistical dependency between the cultural distance, the AVEM patterns, and the sociocultural adaption. With $\chi 2(5)=9.062, p=.11$, no significant difference of the AVEM patterns regarding the cultural distance between the sending country and the home country was obtained; wherefore, H2a could not be confirmed.

\section{Testing Hypothesis $\mathbf{2 b}$}

Results show with $\chi^{2}(3)=7.981, p=.05$ that the mean of sociocultural adaption significantly differs in regard to the AVEM patterns. Therefore, H2b was confirmed. The distribution of AVEM patterns in the sample is presented in Table 4.

\section{Testing Hypothesis 3}

In order to test hypothesis 3, we performed a linear regression analysis, testing whether the experienced appreciation predicts the current societal engagement. Statistical requirements for regression analysis (linearity, normal distribution, homoscedasticity) were fulfilled. The linear regression turns out significant $(\mathrm{F}(3,305)=5.02, \mathrm{p}=.03$; $\mathrm{R}^{2}=.03$ ), explaining $3.5 \%$ of the variance of the criterion current societal engagement.

Table 3 Pairwise t-test comparison

\begin{tabular}{|c|c|c|c|c|c|c|}
\hline Country & Europe & Latin America & Anglo & sub-Sah. Africa & Middle East & South East Asia \\
\hline \multicolumn{7}{|l|}{ Europe } \\
\hline Latin America & $\begin{array}{c}t(5)=.47 \\
p=.65\end{array}$ & & & & & \\
\hline Anglo & $\begin{array}{c}t(7)=-.37 \\
p=.71\end{array}$ & $\begin{array}{c}t(53)=-1.35 \\
p=.18\end{array}$ & & & & \\
\hline sub-Saharan Africa & $\begin{array}{c}t(5)=.87 \\
p=.41\end{array}$ & $\begin{array}{c}t(84)=1.50 \\
p=.14\end{array}$ & $\begin{array}{c}t(35)=2.1 \\
p=.04\end{array}$ & & & \\
\hline Middle East & $\begin{array}{c}\mathrm{t}(53)=1.01 \\
\mathrm{p}=.358\end{array}$ & $\begin{array}{c}t(17)=2.06 \\
p=.06\end{array}$ & $\begin{array}{c}t(7)=3.44 \\
p=.01\end{array}$ & $\begin{array}{c}t(38)=.25 \\
\mathrm{p}=.80\end{array}$ & & \\
\hline South East Asia & $\begin{array}{c}t(5)=.79 \\
p=.46\end{array}$ & $\begin{array}{c}t(7)=1.09 \\
p=.28\end{array}$ & $\begin{array}{c}t(26)=1.9 \\
p=.05\end{array}$ & $\begin{array}{c}t(5)=-.27 \\
p=.79\end{array}$ & $\begin{array}{c}\mathrm{t}(20)=-.70 \\
\mathrm{p}=.49\end{array}$ & \\
\hline
\end{tabular}


Table 4 Distribution of AVEM patterns in the sample

\begin{tabular}{llll}
\hline Sociocultural adaption & Pattern AVEM & $\mathrm{N}$ & $\%$ \\
\hline & Pattern G & 47 & $15 \%$ \\
& Pattern S & 146 & $47 \%$ \\
& Risk pattern A & 34 & $12.5 \%$ \\
Risk pattern B & 34 & $12.5 \%$ \\
& other & 41 & $13 \%$ \\
total & 302 & $100 \%$ \\
\hline
\end{tabular}

Appreciation has with a $\beta=.19(\mathrm{p}=.04)$ a small but significant influence on the current societal engagement of development workers. With that, hypothesis 3 can be confirmed.

\section{Discussion}

This research was conducted to investigate the reintegration process of development workers. We therefore payed special attention to the sociocultural adaption and the further engagement of returned German development workers, in relation to the cultural distance between host and home culture, the experiential and behavioral patterns, and the perceived worshiping of their efforts. The following section discusses the results and derives practical implications.

Contrary to hypothesis 1 , pairwise t-tests showed significant differences between the means of sociocultural adaption only for the regional comparison Anglo-sub-Saharan Africa and Anglo-Middle East. This is not in line with the suggestion of Wolff (2017) that the cultural distance plays an important role for the adaption and reculturation process. Furthermore, the manifestations of the AVEM patterns do not differ significantly for different cultural regions, thus contradicting hypothesis $2 \mathrm{a}$. Yet, hypothesis $2 \mathrm{~b}$ could be confirmed. The analysis reveals significant mean differences of sociocultural adaption after return between participants with different manifestations of the AVEM patterns (H2b).

Previous studies, which investigated reintegration processes, mainly focused on the assimilation of employees of multinational enterprises returning from international assignments at departments abroad (Hurn, 1999; Adler, 1981; Martin, 1984; Suutari \& Välimaa, 2002; Sussman, 2001 and others). Those studies imply that employees who have a more social-oriented working style are more likely to adapt to another culture quickly. Moreover, there is a consensus that irrespective of the attitudes towards work, repatriates require special support in order to deal with the hassles of coming "home." However, only a few published studies investigated the rehabilitation of development workers. The already introduced studies of DEval and the studies of Koch and Widmaier (2006) included this aspect (Roxin et al., 2015). The analysis of the workrelated behavioral and experiential patterns demonstrates that the majority of the questionees can be assigned to the patterns $\mathrm{S}$ and $\mathrm{G}$. Respective patterns display a rest and health-oriented attitude in the working context. Twenty-eight percent of the 
participants, however, display the risk patterns A or B. We predicted and found that they appear to be related to less sociocultural adaption after return. Considering Scharbert (2015) description of reactions to reculturation to a home organization, this implies that development workers with different work and coping traits are likely to be more or less socioculturally adapted to a certain organization. This does not necessarily mean that this depends on the stay abroad, as it is not clear in how far such traits changed during the time abroad (Wolff, 2017). However, the results indicate that development workers who return home have to face hassles of reculturation, irrespective of the country they stayed in, and if they are not coping with stress in a healthy way, they are at special risk to remain poorly or at least less adapted.

While the first part of this article focused on the sociocultural adaption of development workers, the second part aimed to show that the appreciation of the fulfilled task abroad influences the later engagement of former development workers. A survey in 2013 on the topic of societal engagement of former development workers clarified that this group is voluntarily active above average (GIZ, n.d.), in general. Business Psychology shows that appreciation can be both, a possible inhibitor when lacking or an extra motivation for employees (White, 2016). However, the importance of experienced appreciation usually varies within a sample (Muntz \& Dormann, 2020). Using a qualitative study design, Dieleman et al. (2006) found that next to salary responsibility and appreciation of engagement were the strongest motives among health workers in Mali. The study at hand could reveal that the experienced appreciation towards the fulfilled task abroad had a significant linear relationship with the societal engagement in the regression model. This implies that social worshiping is of special importance for development workers, which is not much of a surprise and has been outlined by several other studies (e.g., Templer et al., 2010, the DEval study, and the study of Koch \& Widmaier, 2006). Previous studies also show that the certainty to have a job after their task abroad was the second most supporting. As number one factor, council, seminar courses for homecomers, and training opportunities were mentioned. Hereby, the focus was on council and training opportunities. With that, the result of this study that appreciation of the fulfilled task abroad predicts later engagement indicates that job search is not a problem rooted in practical difficulties after the return rather than in social support. Moreover, when personal estimations are inquired, many homecomers wish for more support regarding the job search (Templer et al., 2010). At best, support should be given already before the return, as advised by several acculturation models. Both aspects, certainty to find a job and supporting measures, have been described by terms of worshiping the work of development workers, or more precisely: The lack of such opportunities has been experienced as a lack of appreciation (Koch \& Widmaier, 2006).

Moreover, this indicates that considering highly engaged, well-skilled workforce, failing to meet their basic motivations to work is a big waste of potential. To increase further engagement, the factor appreciation should gain the attention of employers of organizations such as Engagement Global. Engagement Global is the contact point in Germany for civil and communal engagement with development work (Global Engagement, 2016). This is in line with the recommendations of Dieleman et al. (2006) who emphasize the importance of well-structured systems that contribute to the general appreciation of development workers in organizations. These organizations can play a major role in encouraging returning development workers to strive for societal engagement and in turn to catalyze their integration process. 


\section{Limitations}

The study at hand had some limitations. The descriptive statistics already demonstrated that the sample was very heterogeneous. The age range of the group was between 20 and 82 years $(M=50.1)$, and statements about the length of the assignments as development worker ranged from 1 to 40 years as maximum length $(\mathrm{M}=7.59)$. The distribution of the statements regarding the type of development organization is too versatile to categorize. However, the dependent and independent variables did not relate significantly to age, sex, and migration background. Further investigations in this field should inquire questions concerning the occupational situation more strategically, which would help to understand the further engagement in greater detail. Moreover, the time since the return should be considered as a possible covariate. The interpretation and discussion of the results also reveal that future studies should include the experienced structural support and acculturation in order to predict current societal engagement of development workers with regression analyses. Wolff (2017) outlines in his discussion of the measurement of character changes abroad that post-tests should take place immediately after the stay. Future investigations also should consider the factor stress after the return. A variety of studies has proven that the return can cause high emotional stress for the expatriates. This factor should also be investigated for returning development workers. Hereby, it is important that homecomers are questioned right after, and a few months after the return to obtain more exact values. Another factor worth investigating is the type of job, in what region the development worker followed his/her international assignment, and to what extent the reintegration varies. However, as life changing events are expected to show longlasting effects (Tracy-Ventura et al., 2016), cross-sectional designs should be valid, when building on a profound theoretical framework. However, in order to exclude this possible covariate, future studies should at least asses the time since the stay abroad. Hereby, it would be useful to collect the statements from 100 participants for each type of development organization (state, private, clerical) to create a good basis for comparison purposes and to derive significant results from that. As in the DEval study, a minimum return date since the homecoming should be set, since different influences can be only expected after 1 year. However, there should be also a maximum time span since the return, because many memories about experiences might have vanished. Finally, we suggest for further investigations to assess the aspects of the returning process, such as employment status after the return, support for returnees, perceived stress, and social integration in order to better understand what happens after development workers return. Therefore, studies should also consider expectations and actual experiences, probably in a pre-post design before and after the return. Values and attitudinal change of returning co-workers are further aspects, which are of psychological nature and for which more investigation would be useful. What did the assignment abroad as a development worker cause within the individual? How did the person change? Moreover, which factors contributed the most to this change?

\section{Conclusion}

The study at hand showed that the sociocultural adaption of development workers after their return was significantly related to their work-related personality. Results indicate 
that individuals who are more actively working together with others might be more likely to readapt well after return. Moreover, the results showed that experienced social appreciation of the stay abroad is a relevant predictor of further engagement. Previous studies (Roxin et al., 2015; Koch \& Widmaier, 2006) indicate, that among social appreciation, also the security of the job, and seminar courses are considered as signs of occupational appreciation. Considering that appreciation is very likely to be a central motive for development workers, this underlines the importance for organizations to worship the engagement of repatriating development workers by offering support as well as by creating a culture in which extraordinary engagement is honored sufficiently. Thereby, organizations should consider the role of coping with stress and cooperating demonstrated in this study. We suggest to offer programs that ensure social inclusion, such as mentoring programs.

Funding Open Access funding enabled and organized by Projekt DEAL.

Availability of data and material Data is available on request.

Code availability Not applicable

\section{Declarations}

Conflict of interest The authors declare no competing interests.

Open Access This article is licensed under a Creative Commons Attribution 4.0 International License, which permits use, sharing, adaptation, distribution and reproduction in any medium or format, as long as you give appropriate credit to the original author(s) and the source, provide a link to the Creative Commons licence, and indicate if changes were made. The images or other third party material in this article are included in the article's Creative Commons licence, unless indicated otherwise in a credit line to the material. If material is not included in the article's Creative Commons licence and your intended use is not permitted by statutory regulation or exceeds the permitted use, you will need to obtain permission directly from the copyright holder. To view a copy of this licence, visit http://creativecommons.org/licenses/by/4.0/.

\section{References}

Adler, N. (1981). Re-entry: Managing cross-cultural transitions. Group and Organization Studies, 6, 341-356. https://doi.org/10.1177/105960118100600310 .

Assari, S. (2020). Income and mental well-being of middle-aged and older Americans: Immigrants' diminished returns. International Journal of Travel Medicine and Global Health, 8(1), 37-43. https://doi.org/ 10.34172/ijtmgh.2020.06 .

Barmeyer, C. (2010). Kultur in der interkulturellen Kommunikation. In Interkulturelle Kommunikation und Kulturwissenschaft (pp. 13-34). Karl Stutz-Verlag.

Berry, J., Poortinga, Y., Breugelmans, S., Chasiotis, A., \& Sam, D. (2011). Cross-cultural psychology: Research and applications. University Press.

Dieleman, M., Toonen, J., Touré, H., \& Martineau, T. (2006). The match between motivation and performance management of health sector workers in Mali. Human Resources for Health, 4(1), 2-27.

Georgas, J., \& Papastylianou, D. (1994). The effect of time on stereotypes: Acculturation of children of returning immigrants to Greece. In Georgas, J., \& Papastylianou, D. (eds.) Journeys into cross-cultural psychology (235-262). 
GIZ (n.d.). Arbeiten als Entwicklungshelfer/in (Working as a development worker). Retrieved from https:// www.giz.de/Entwicklungsdienst/de/html/1422.html. Accessed 24.06.2021.

Global Engagement (2016). Wer wir sind. Retrieved from https://www.engagement-global.de/wer-wir-sind. html. Accessed 24.06.2021.

Gullahorn, J. E., \& Gullahorn, J. T. (1963). American students abroad: Professional versus personal development. The Annals, 368, 43-59.

House, R., Hanges, P., Javidan, M., Dorfman, P. W. \& Gupta, V. (2004). Culture, leadership, and organizations. The Globe Study of 62 Societies. Sage.

Hurn, J. (1999). Return - The toughest assignment of all. Industrial and Commercial Training, 3, $224-228$. https://doi.org/10.1108/00197859910291397.

Kauffeld, S. (2014). Arbeits-, Organisations- und Personalpsychologie für Bachelor. Springer.

Kim, Y. Y. (2008). Acculturation Processes and Communication. The International Encyclopedia of Communication. Wiley Online.

Koch, J., \& Widmaier, C. (2006). Untersuchung zur beruflichen und sozialen Reintegration ehemaliger Entwicklungshelfer und Entwicklungshelferinnen. Im Auftrag von Arbeitsgemeinschaft der Entwicklungsdienste (AGdD).

Kompreni (2009). Glossar für Interkulturelle Terminologie, Retrieved from http:/www.kompreni.com/de/ interkulturelles-glossar.html. Accessed 24.06.2021.

Kristjánsdóttir, H., Guðlaugsson, P. Ö., Guðmundsdóttir, S., \& Aðalsteinsson, G. D. (2017). Hofstede national culture and international trade. Applied Economics, 49(57), 5792-5801.

Lackner, K. (2008). Expatriation: Entsendung ohne Wiederkehr? Gruppendynamik und Organisationsberatung, 1, 64-87. https://doi.org/10.1007/s11612-008-0007-1 .

Mägdefrau, J., \& Genkova, P. (2014). Der Zusammenhang von kultureller Distanz, kultureller Anpassung und beruflichem Belastungserleben: Eine Studie zum Gelingen der Entsendung von Lehrkräften im deutschen Auslandsschulwesen. Paradigma, 7, 68-84.

Mapp, S. C. (2012). Effect of short-term study abroad programs on students' cultural adaptability. Journal of Social Work Education, 48, 727-737.

Martin, J. (1984). The intercultural reentry: Conceptualization and directions for future research. International Journal of Intercultural Relocation, 8, 115-134. https://doi.org/10.1016/0147-1767(84)90035-X .

Muntz, J., \& Dormann, C. (2020). Moderating effects of appreciation on relationships between illegitimate tasks and intrinsic motivation: A two-wave shortitudinal study. European Journal of Work and Organizational Psychology, 10, 1-14.

Neto, F. (2012). Re-acculturation and adaption among adolescents from returned Portuguese immigrant families 1. Journal of Applied Social Psychology, 42(1), 133-150.

Panicacci, A., \& Dewaele, J. M. (2017). 'A voice from elsewhere': Acculturation, personality and migrants' self-perceptions across languages and cultures. International Journal of Multilingualism, 14(4), 419-436.

Redfield, R., Linton, R., \& Herskovits, M. J. (1936). Memorandum for the study of acculturation. American Anthropologist, 38, 149-152.

Roberts, B. W., Wood, D., \& Smith, J. L. (2005). Evaluating Five Factor Theory and social investment perspectives on personality trait development. Journal of Research in Personality, 39(1), 166-184. https://doi.org/10.1016/J.JRP.2004.08.002 (Journal of Research in Personality, 39(1), 166-184.

Rossi, R. (2015). Repatriierung: Eine Einführung in internationale Verlegungstransporte. Springer-Verlag.

Roxin, H., Schwedersky, T., Polak, J., Vorwerk, K., \& Gaisbauer, F. (2015). Entwicklungshelferinnen und Entwicklungshelfer - ein Personalinstrument der deutschen Entwicklungszusammenarbeit. Deutsches Evaluierungsinstitut der Entwicklungszusammenarbeit (DEval).

Sam, D. L., \& Berry, J. W. (2011). Acculturation: When individuals and groups of different cultural backgrounds meet. Perspectives on Psychological Science, 5(4), 20-45.

Schaarschmidt, U., Fischer, A. W. (1996). A questionnaire for the assessment of work motivation: Arbeitsbezogenes Verhaltens- und Erlebensmuster (AVEM). Zeitschrift für Arbeits- und Organisationspsychologie, 38. Retrieved from http://search.ebscohost.com/login.aspx?direct=true\&db= edswis\&AN=edswis.XPSYF63C6B147E9469569F34B679F43A4578\&lang=de\&site=eds-live. Accessed 24.06.2021.

Schaarschmidt, U., \& Fischer, A. W. (2008). AVEM - Arbeitsbezogenes Verhaltens- und Erlebensmuster. Pearson.

Scharbert, K. (2015). Reintegration der Mitarbeiter nach Auslandsentsendungen: Parallelmodell für die Praxis. Diplomica Verlag GmbH.

Sussman, N. (2001). Return transitions: Psychological preparedness, cultural identity, and attributions among American managers. International Journal of Intercultural Relations, 25, 109-123. https://doi.org/10. 1016/S0147-1767(00)00046-8 . 
Sussman, N. (2002). Testing the cultural identity model of the cultural transition cycle: Sojourners return home. International Journal of Intercultural Relations, 26, 391-408. https://doi.org/10.1016/S01471767(02)00013-5.

Suutari, V., \& Välimaa, K. (2002). Antecedents of return adjustment: New evidence from Finnish repatriates. International Journal of Manpower, 23, 617-634. https://doi.org/10.1108/01437720210450798 .

Templer, A., Armstrong-Stassen, M., \& Cattaneo, J. (2010). Antecedents of older workers' motives for continuing to work. Career Development International. 2.

Thomas, A. (2003). Psychologie interkulturellen Lernens und Handelns. In A. Thomas (Ed.), Kulturvergleichende Psychologie. Hogrefe.

Tracy-Ventura, N., Dewaele, J.-M., Köylü, Z., \& McManus, K. (2016). Personality changes after the 'year abroad'? A mixed-methods study. Study Abroad Research in Second Language Acquisition and International Education, 1(1), 107-127. https://doi.org/10.1075/sar.1.1.05tra .

Ward, C. (2001). The A, B, Cs of Acculturation. In D. Matsumoto (Ed.), The handbook of culture and psychology (pp. 411-445). Oxford University Press.

Ward, C., \& Geeraert, N. (2016). Advancing acculturation theory and research: The acculturation process in its ecological context. Current Opinion in Psychology, 8, 98-104.

Ward, C., \& Kennedy, A. (1999). The measurement of sociocultural adaption. International Journal of Intercultural Relocation, 23, 659-677. https://doi.org/10.1016/S0147-1767(99)00014-0 .

White, P. (2016). Appreciation at work training and the motivating by appreciation inventory: Development and validity. Strategic HR Review, 3, 15-27.

Wirth, E. (1992). Mitarbeiter im Auslandeinsatz - Planung und Gestaltung. Gabler-Verlag.

Wolff, F. (2017). Interkulturelle Kompetenz durch Auslandsaufenthalte. Springer Fachmedien Wiesbaden. https://doi.org/10.1007/9783658163921 .

Zick, A. (2010). Psychologie der Akkulturation. VS Verlag für Sozialwissenschaften I GWV Fachverlage $\mathrm{GmbH}$.

Publisher's Note Springer Nature remains neutral with regard to jurisdictional claims in published maps and institutional affiliations. 